\title{
Power analysis of the basilar membrane in the cochlea by mechanical resonance
}

\author{
Análisis de potencia de la membrana basilar en la cóclea por resonancia mecánica
}

\section{Jiménez-Hernández}

Escuela Superior de Ingeniería Mecánica y Eléctrica, Instituto Politécnico Nacional, Ciudad de México, México.

\begin{abstract}
This paper presents the power analysis to the mechanical model of the basilar membrane in the cochlea as a system of forced damped harmonic oscillators without lateral coupling proposed by Lesser and Berkeley. The Lagrange's equation for dissipative mechanical systems and the energy method are used to obtain the general equation of the system. Next a solution by complex exponential is proposed using the resonance analysis considering only excitations of pure tones to obtain the equation of displacement, and with its derived the equation of velocity. The power in the system is the multiplication between the equations of the velocity and the excitation force. Finally the equation of the average power in the system is obtained. This new solution has the advantage of determining the relationship between the excitation frequency of the system and the position along the basilar membrane where the average power is maximum. This implies that the distance where there is maximum transfer of energy between the wave propagating in the perilymph and the mechanical displacement of the basilar membrane on the hair cells in the organ of Corti is known. The power analysis is successfully compared with the two-dimensional model of the cochlea developed by Neely using finite differences and with the experimental results of Békésy. In both experiments are used the same mechanical parameters of the basilar membrane and the same set of frequencies of evaluation proposed in the original papers in order to compare the different methodologies.
\end{abstract}

KEYWORDS: Cochlea, basilar membrane, mechanical resonance, power. 


\section{RESUMEN}

En este artículo se presenta el análisis de potencia del modelo mecánico de la membrana basilar en la cóclea como un sistema de osciladores armónicos forzados amortiguados sin acoplamiento lateral propuesto por Lesser y Berkeley. Se usa la ecuación de Lagrange para sistemas mecánicos disipativos y el método de energías para obtener la ecuación general del sistema. A continuación se propone su solución en forma exponencial compleja usando el análisis por resonancia considerando únicamente excitaciones de tonos puros obteniendo la ecuación del desplazamiento, y a partir de su derivada la ecuación de la velocidad. Posteriormente se determina la ecuación de potencia mediante el producto entre las ecuaciones de la velocidad y la fuerza de excitación. Por último se obtiene la ecuación de la potencia promedio en el sistema. Esta nueva solución tiene la ventaja de determinar la relación entre la frecuencia de excitación del sistema y la posición a lo largo de la membrana basilar donde la potencia promedio es máxima, con lo cual se conoce la distancia donde se genera la máxima transferencia de energía entre la onda que se propaga en la perilinfa y el desplazamiento mecánico de la membrana basilar sobre los cilios en el órgano de Corti. El análisis de potencia se compara satisfactoriamente con el modelo en dos dimensiones por diferencias finitas de la cóclea desarrollado por Neely y con los resultados experimentales obtenidos por Békésy. En ambos experimentos se usan los mismos parámetros mecánicos de la membrana basilar y el mismo conjunto de frecuencias de evaluación propuestos en los trabajos originales con el objetivo de comparar las diferentes metodologías.

PALABRAS CLAvE: Cóclea, membrana basilar, resonancia mécanica, potencia.

\section{Correspondencia}

DESTINATARIO: Mario Jiménez Hernández

INSTITUCIÓN: Escuela Superior de Ingeniería Mecánica

y Eléctrica Unidad Zacatenco, Instituto Politécnico

Nacional, Laboratorio de Física

DIRECCIÓN: Av. Luis Enrique Erro S/N, Unidad

Profesional Adolfo López Mateos, Zacatenco,

Delegación Gustavo A. Madero, C. P. 07738, Ciudad de

México, México.

CORREO ELECTRÓNICO: mjimenezh@ipn.mx

\section{Fecha de recepción:}

1 de julio de 2016

Fecha de aceptación:

27 de septiembre de 2016 


\section{INTRODUCTION}

This paper presents the power analysis for the two-dimensional model of the basilar membrane as a set of forced damped harmonic oscillators without lateral coupling proposed by Lesser and Berkeley, the objective is to determine the relationship between the excitation frequency and the position along of the basilar membrane where the maximum average power occurs. This model has the advantage over the previous models of to obtain the distance where there is maximum energy transfer between the basilar membrane and the organ of Corti, which is necessary for the activation of the hair cells.

The two-dimensional models of the mechanical tuning of the basilar membrane in the cochlea have been proposed considering the perilymph as an incompressible fluid and the basilar membrane as a forced oscillator damped without coupling along the length of the membrane. The most representative models were developed by Peterson and Bogert ${ }^{[1]}$, Ranke ${ }^{[2]}$, Fletcher ${ }^{[3]}$, Zwislocki ${ }^{[4]}$, Lesser and Berkeley ${ }^{[5]}$ and Siebert ${ }^{[6]}$, the contribution of these models is to determine the physical propagation of the wave on the basilar membrane by short-wave and Long-Wave approximations. In these models are proposed parameters of mass, elasticity and damping that representing the mechanical behavior of amplitude and phase in the wave on the basilar membrane in the same way that the observations reported by Békésy [7].

However these models have disadvantages to represent the behavior of the membrane for the high frequencies near to the apex and for the low frequencies near to the helicotrema. The later models consider the basilar membrane as an elastic plate, the viscosity of the perilymph and the geometry of the membrane, being the most representative developed by Steele ${ }^{[8]}$, Inselberg and Chadwick ${ }^{[9]}$, Chadwick, Inselberg and Johnson $^{[10]}$, Chadwick ${ }^{[11]}$ and Holmes ${ }^{[12,13,14]}$, with which were developed the Shallow-Water and DeepWater approximations.
Numerical solutions for the two-dimensional models of the cochlea have been developed by Lesser and Berkeley using Fourier series ${ }^{[5]}$ and by Allen from the Green's function $^{[15]}$. Later Allen and Shondi consider a recursive algorithm to solve the model in the time domain ${ }^{[16]}$. Steele and Taber proposed a solution using the finite difference method ${ }^{[17,18]}$. Viergever use the Laplace equation in three dimensions to model the behavior of the basilar membrane ${ }^{[19]}$ and Neely uses the finite difference method to discretize the Laplace equation $^{[20,21]}$. Subsequently Neely made a mathematical model of the cochlea considering its macromechanics and micromechanics ${ }^{[22]}$, in a later work Neely proposed a model for the motility of the outer hair cells in the tunning of the basilar membrane ${ }^{[23]}$. Compilations of the two-dimensional models of the cochlea have been prepared by Dallos et al. ${ }^{[24]}$, Dallos, Popper and Fay ${ }^{[25]}$ Keener and Sneyd ${ }^{[26]}$ and Duifhuis ${ }^{[27]}$. Applications of these models to disorders of hearing have been published by Berlin and Bobbin ${ }^{[28,29]}$.

Certainly of all two-dimensional models that have been developed one of the best approaches to the macro-mechanical response of the cochlea has been developed by Lesser and Berkeley, which considers the variation of dimensions in the basilar membrane along of the scale vestibuli and the scala tympani, also models the opening of the helicotrema and proposes mechanical parameters for the impedance of the basilar membrane that provides a similar response to the observations of Békésy. The best analytical solution for this type of models has been developed by Neely, in which the mechanical parameters of admittance for the basilar membrane that are proposed improve the results of all observations in the experiments obtained previously of the mechanical behavior of the basilar membrane, being until today one of the best model in two-dimensions for the cochlear mechanics. Recently, this methodology and their mechanical parameters has been employed in several works, Ramamoorthy, Deo and Grosh $^{[30]}$ made an electric mechanical model 
of the cochlea response. Liu and Neely ${ }^{[31]}$ consider the nonlinear effects in the mechanoelectrical transduction of the outer hair cells. Elliot, Lineton and $\mathrm{Ni}^{[32]}$ studied the fluid coupling in the cochlear mechanics, a more comprehensive study of this methodology was developed by $\mathrm{Ni}^{[33]}$. Jiménez employment the resonance analysis ${ }^{[34,35]}$ to solve these types of models. Elliot, Ni, Mace and Lineton ${ }^{[36]}$ developed a finite element analysis of the passive cochlea. Cormack, Liu, Nam and Gracewski ${ }^{[37]}$ model the fluid coupling of the behavior between the basilar membrane and the tectorial membrane and Jiménez used the Lagrange's equation $^{[38]}$ to determine the coupling between the macromechanics of the cochlea and the micromechanics in the organ of Corti.

In the analysis of power proposed first is obtained the general equation of the system using the Lagrange's equation for dissipative systems. Next the resonance analysis is used to obtain the equation of displacement of the system and from its derivative the equation of the velocity. The power in the system is the product of the equations of the velocity and the excitation force. Finally as in this analysis the excitation force is a cosine function the average power is considered.

For the evaluation of the power analysis, the value of the magnitude of the force is normalized and the same set of frequencies reported in the original papers are considered, in order to compare the results between the different methodologies. In the first experiment the mechanical parameters of admittance for the two-dimensional model of the cochlea developed by Neely are used to compare the power analysis with the method of finite differences applied to the Laplace equation. In a second experiment are used the values of the mechanical parameters of impedance along of the basilar membrane developed by Lesser and Berkeley to compare the results of the power analysis with the experimental measurements of Békésy, obtaining satisfactory results in both experiments.
The advantage of this methodology respect to the last

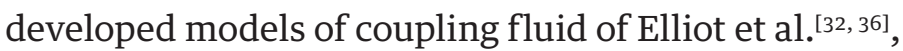
$\mathrm{Ni}^{[33]}$ and Cormack et al. ${ }^{[38]}$ is determining the relationship between the excitation frequency of the system and the distance along of the basilar membrane considering only their mechanical characteristics of mass, stiffness and damping. In contrast the other methodologies required to determine the position where the wave that is propagated in the perilymph has a maximum value, also the power analysis modeling the response of the cochlear mechanics without considering the mechanical behavior of the organ of Corti, which is corroborated by the results obtained in the developed experiments.

\section{Two-dimensional model of the cochlea}

The cochlea is the element of the inner ear that identifies the frequencies that constitute a sound, it has spiral geometry and is divided longitudinally into three compartments: the scala vestibuli, the scala tympani and the scala media. The scala vestibuli and the scala tympani are filled with a fluid called perilymph and the scala media is filled with a fluid of high concentration in potassium and low in sodium called endolymph. The scala vestibuli and the scala media are separated by the Reissner's membrane and the scala media and the scala tympani are separated by the basilar membrane ${ }^{[26]}$.

The stapes located at the base of the cochlea transmits the vibrations from the middle ear to the scala vestibuli through the oval window, the resulting waves are propagated in the perilymph along of the scala vestibuli and create complementary waves in the basilar membrane and the scala tympani.

At the end of the cochlea or apex there is an opening called helicotrema that allows leveling the pressures between the two compartments, as the perilymph is an incompressible fluid exists a complementary structure to the oval window in the scala tympani called the round window ${ }^{[39]}$. 
The transduction of the sound wave into electrical signals occurs in the hair cells which are placed in the organ of Corti on the basilar membrane, when the waves are propagated in the perilymph the basilar membrane generates a force on them causing a change in the electrical potential which is transmitted to the brain by the auditory nerve ${ }^{[7]}$.

The mechanical characteristics of the cochlea have been modeled in two-dimensional by Lesser and Berkeley. Their model considers to the perilymph as an incompressible fluid with a fixed volume and that only can be moved inside due to the excitations transmitted by the oval window into the scala vestibuli. This has the advantage of generalizing the behavior of the cochlea in two rectangular compartments which represent to the scala vestibuli and the scala tympani separated by the basilar membrane. If the fluid $\varphi$ is irrotational, the density $\rho$ always is constant and the pressure $p$ is normalized then is possible to eliminate the nonlinear terms when the amplitudes are small, obtaining the following two conditions

$$
\begin{gathered}
\rho \frac{\partial \phi}{\partial t}+p=0 \\
\nabla^{2} \phi=0
\end{gathered}
$$

If two compartments are considered, there are two copies of the equations which model the mechanical behavior of the cochlea.

$$
\begin{gathered}
\rho \frac{\partial \phi_{1}}{\partial t}+p_{1}=\rho \frac{\partial \phi_{2}}{\partial t}+p_{2}=0 \\
\nabla^{2} \phi_{1}=\nabla^{2} \phi_{2}=0
\end{gathered}
$$

Lesser and Berkeley proposed that each point of the basilar membrane is modeled as a simple forced damped harmonic oscillator with mass $m(x)$, damping $c(x)$ and stiffness $k(x)$ that vary along of the length on the basilar membrane and that the displacement $\eta$ of the membrane is a function of the position and the time specified by

$$
m(x) \frac{\partial^{2} \eta}{\partial t^{2}}+c(x) \frac{\partial \eta}{\partial t}+k(x) \eta=p_{2}(x, \eta, t)-P_{1}(x, \eta, t)
$$

The mechanical parameters of the basilar membrane proposed by Lesser and Berkeley are shown in the Table 1.

The numerical solution developed by Nelly to the model of cochlear mechanics of Lesser and Berkeley proposes that the cochlea is a rectangular region of length $L$ from the base to the apex and width $2 \mathrm{H}$, this is filled with an incompressible fluid similar to the perilymph and divided into two symmetrical compartments, which are separated by an elastic partition of similar characteristics to the basilar membrane. The first compartment represents the scale vestibuli and is limited to the outside by the stapes, the upper wall and the helicotrema, the second represents the scala tympani and is limited to the outside by the round window, the lower wall and also by the helicotrema. The movement of the stapes sets in motion to the perilymph and causes deformation in the basilar membrane, the Figure 1 shows the original two-dimensional model of the cochlea proposed by Neely ${ }^{[20]}$.

TABLE 1. Cochlear parameters by Lesser and Berkeley.

\begin{tabular}{ccc}
\hline Parameter & Value & Units \\
\hline$m(x)$ & 0,05 & $g / \mathrm{cm}^{2}$ \\
$k(x)$ & $10^{9} e^{-3 x}$ & $d y n / \mathrm{cm}^{3}$ \\
$c(x)$ & $3000 e^{-1,5 x}$ & $d y n \cdot s / \mathrm{cm}^{3}$ \\
\hline
\end{tabular}




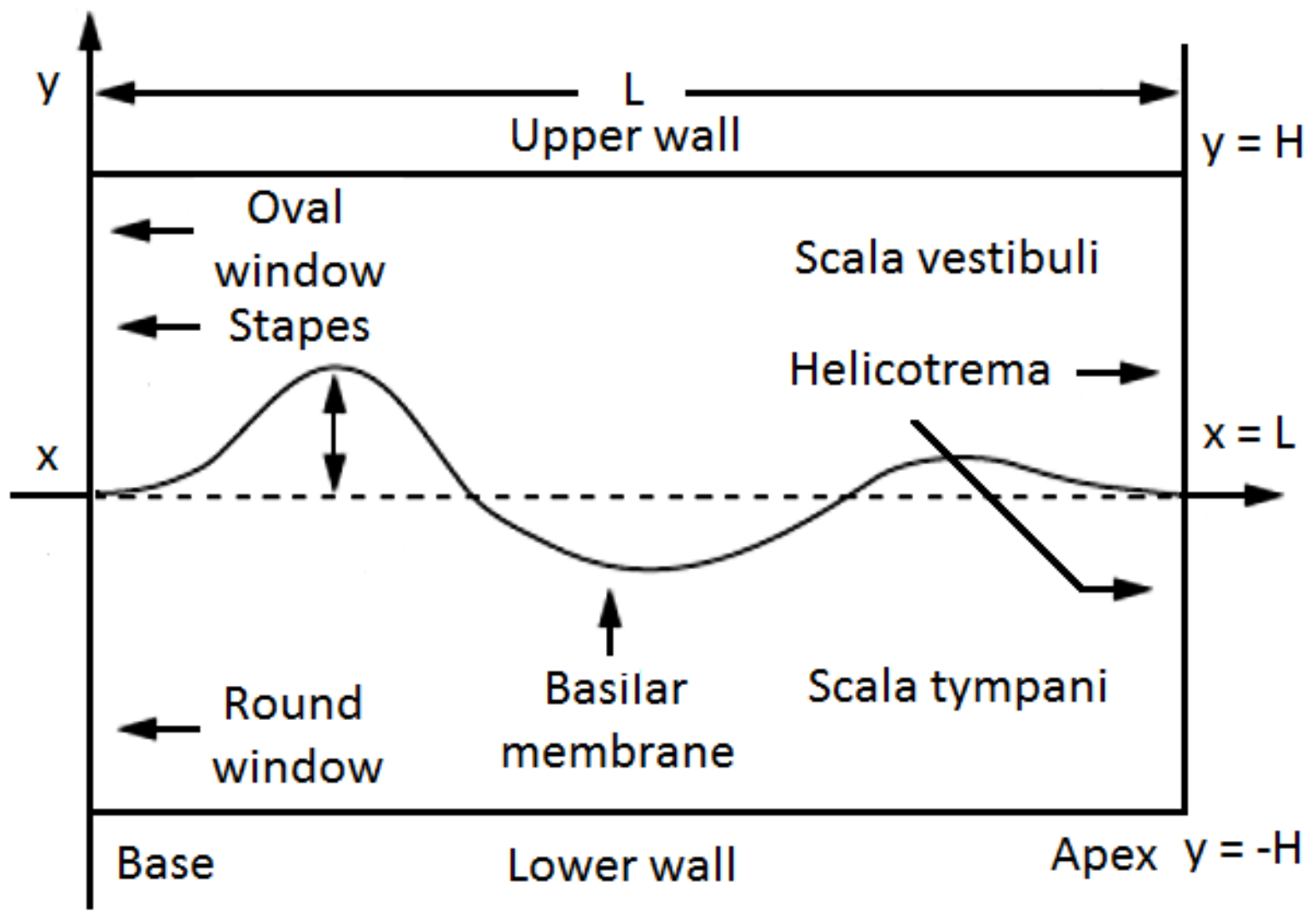

FIGURE 1. Two dimensional model of the cochlea.

Therefore the fluid is the only means of propagation of the longitudinal wave, when there is a sinusoidal excitation the pressure in the fluid $P_{d}(x, y)$ is the difference between the pressure in the scala tympani $P_{s t}(x$, $y$ ) and the pressure in the scala vestibuli $P_{s v}(x, y)$ which is given by the following expression

$P_{d}(x, y)=P_{s v}(x, y)-P_{s t}(x, y)$

The force generated by the movement of the basilar membrane in the axis y within the interval $0<x<L$ is due to the acceleration $a_{b}(x)$ of the mass of fluid, if the density $\rho$ is known then the boundary condition is

$\frac{\partial}{\partial y} P_{d}(x, 0)=2 \rho a_{b}(x)$
This acceleration of the basilar membrane $a_{b}$ is then a function of the pressure difference and the admittance $Y(x)$ of the form

$a_{b}(x)=j \omega Y(x) P_{d}(x, 0)$

The movement of the basilar membrane is always considered linear and without longitudinal coupling, their mechanical properties are represented by an admittance function $Y(x)$ that depends of the physical characteristics along of their length of mass $m(x)$, stiffness $k(x)$ and damping $c(x)$ of the form

$$
Y(x)=\frac{1}{c(x)+j\left[\omega m(x)-\frac{k(x)}{\omega}\right]}
$$


And therefore the impedance $Z(x)$ along the basilar membrane is the inverse of the admittance $Y(x)$, which is given by

$$
Z(x)=c(x)+j\left[\omega m(x)-\frac{k(x)}{\omega}\right]
$$

In the Table 2 are shown the parameters of admittance of the basilar membrane as a function of the distance from the stapes proposed by Neely.

TABLE 2. Cochlear parameters by Neely.

\begin{tabular}{ccc}
\hline Parameter & Value & Units \\
\hline$m(x)$ & 0,15 & $g / \mathrm{cm}^{2}$ \\
$k(x)$ & $10^{9} e^{-2 x}$ & $d y n / \mathrm{cm}^{3}$ \\
$c(x)$ & 200 & dyn $\cdot \mathrm{s} / \mathrm{cm}^{3}$ \\
\hline
\end{tabular}

\section{Mechanical resonance}

\section{in the basilar membrane}

The objective of this research is to determine the relationship between the excitation frequency and the distance along of the basilar membrane where the average power is maximum. This establishes the condition of maximum mechanical energy transfer between the basilar membrane and the organ of Corti necessary for the activation of the hair cells. The equation of power in the system is the product of the equation that modeling the velocity and the equation of the excitation force, in order to determine the equation of velocity first is necessary to know the equation of displacement as a function of impedance.

The general equation of the system is obtained using the Lagrange's equation for dissipative mechanical systems, if a solution for complex exponential is proposed then the equation of displacement in relation to the impedance is determined, the term of amplitude in the real part of the resulting equation is the amplitude of resonance. Considering the kinetic energy $K E$, the potential energy $P E$ and the dissipation energy $D E$, the Lagrange's equation for modeling the displacement $x$ of the basilar membrane is

$\frac{d}{d t} \frac{\partial K E}{\partial \dot{x}}-\frac{\partial K E}{\partial x}+\frac{\partial P E}{\partial x}+\frac{\partial D E}{\partial \dot{x}}=0$

The equations of kinetic energy, potential energy and dissipation energy for the model of the basilar membrane as a forced damped harmonic oscillator proposed by Lesser and Berkeley are given by

$$
\begin{aligned}
K E & =\frac{1}{2} m \dot{x}^{2} \\
P E & =\frac{1}{2} k x^{2} \\
D E & =\frac{1}{2} c \dot{x}^{2}
\end{aligned}
$$

Solving the terms of the Lagrange's equation (11) from the equations of energies for the system implies that

$$
\begin{gathered}
\frac{d}{d t} \frac{\partial K E}{\partial \dot{x}}=m \ddot{x} \\
\frac{\partial K E}{\partial x}=0 \\
\frac{\partial P E}{\partial x}=k x \\
\frac{\partial D E}{\partial \dot{x}}=c \dot{x}
\end{gathered}
$$

The sum of the terms obtained provides the equation of motion for the model of the basilar membrane as a system of forced damped harmonic oscillators and if it is considered that the excitation force $F$ in the stapes is defined by a cosine function of magnitude $F_{0}$ and angular frequency $\omega_{f}$, then the equation of the system is given by

$$
m \ddot{x}+c \dot{x}+k x=F_{0} \cos \left(\omega_{f} t\right)
$$


To get the equation of displacement of the basilar membrane is proposed to provide solution to the general equation (19) by the method of complex exponential, whereby the displacement $\dot{x}$, the velocity $\ddot{x}$, the aceleration $x$ and the force $F$ are defined by

$$
\begin{gathered}
x=A e^{j \omega_{f} t} \\
\dot{x}=j \omega_{f} A e^{j \omega_{f} t} \\
\ddot{x}=-\omega_{f}^{2} A e^{j \omega_{f} t} \\
F_{0} \cos \left(\omega_{f} t\right)=F_{0} e^{j \omega_{f} t}
\end{gathered}
$$

If in the equation of system 19 are replaced the complex solutions, the term of displacement is reduced algebraically and the exponential terms are eliminated, then the equation that defines the displacement $x$ of the basilar membrane is obtained.

$$
\begin{gathered}
-m \omega_{f}^{2} A e^{j \omega_{f} t}+j \omega_{f} c A e^{j \omega_{f} t}+k A e^{j \omega_{f} t}=F_{0} e^{j \omega_{f} t} \\
A e^{j \omega_{f} t}\left(j \omega_{f} c+k-m \omega_{f}^{2}\right)=F_{0} e^{j \omega_{f} t} \\
x=\frac{F_{0} e^{j \omega_{f} t}}{j \omega_{f} c+k-m \omega_{f}^{2}} \\
x=\frac{1}{j \omega_{f}} \cdot \frac{F_{0} e^{j \omega_{f} t}}{c+j\left(m \omega_{f}-\frac{k}{\omega_{f}}\right)}
\end{gathered}
$$

The resulting equation is now in terms of the mechanical impedance $\mathrm{Z}$ of the same shape as the model of Neely (10).

$$
Z=c+j\left(m \omega_{f}-\frac{k}{\omega_{f}}\right)
$$

This equation (28) can be expressed as a phasor $Z=$ $|Z| e^{j} \Theta$, if the angular frequency of excitation is expressed as $\omega=2 \pi f$ and there are considered the mechanical parameters of mass $m(x)$, damping $c(x)$ and stiffness $k(x)$ along of the basilar membrane. Then the terms of magnitude and phase are defined by

$$
\begin{gathered}
|Z|=\sqrt{c(x)^{2}+\left[m(x) 2 \pi f-\frac{k(x)}{2 \pi f}\right]^{2}} \\
\Theta=t g^{-1} \frac{m(x) 2 \pi f-\frac{k(x)}{2 \pi f}}{c(x)}
\end{gathered}
$$

And therefore the equation of the displacement of the basilar membrane can be expressed in the form

$$
\begin{gathered}
x=\frac{1}{j \omega_{f}} \cdot \frac{F_{0} e^{j \omega_{f} t}}{|Z| e^{j \Theta}} \\
x=\frac{1}{j \omega_{f}} \cdot \frac{F_{0}}{|Z|} e^{j\left(\omega_{f} t-\Theta\right)}
\end{gathered}
$$

Using the Euler's identity an expression in terms of functions trigonometric is obtained.

$$
x=\frac{1}{j \omega_{f}} \cdot \frac{F_{0}}{|Z|}\left[\cos \left(\omega_{f} t-\Theta\right)+j \operatorname{sen}\left(\omega_{f} t-\Theta\right)\right]
$$

The real part of the equation (33) represents the physical displacement of the basilar membrane.

$$
x=\frac{F_{0}}{\omega_{f}|Z|} \operatorname{sen}\left(\omega_{f} t-\Theta\right)
$$

If the magnitude of impedance is expressed in the terms of mass $m(x)$, damping $c(x)$, stiffness $k(x)$ and angular excitation frequency $\omega f=2 \pi f$, the amplitude of displacement $A_{x}$ is given by

$$
A_{x}=\frac{F_{0}}{2 \pi f \sqrt{c(x)^{2}+\left[m(x) 2 \pi f-\frac{k(x)}{2 \pi f}\right]^{2}}}
$$


To obtain the equation of the velocity is necessary to derive the equation of displacement (34), having the following

$v=\frac{F_{0}}{|Z|} \cos \left(\omega_{f} t-\Theta\right)$

Again if the angular frequency and the mechanical parameters are replaced in the equation (36), the amplitude of the velocity $A_{v}$ is

$$
A_{v}=\frac{F_{0}}{\sqrt{c(x)^{2}+\left[m(x) 2 \pi f-\frac{k(x)}{2 \pi f}\right]^{2}}}
$$

\section{Physical model of power}

The equation of velocity that models the behavior of the basilar membrane indicates that for each exitacion frequency corresponds a distance along of the membrane where the amplitude has a maximum value and therefore the kinetic energy is also maxima.

If the power in the system is known also it is possible to determine the position on the membrane where there is maximum energy transfer, which allows the activation of the hair cells in the organ of Corti.

The power $p$ in the model of the basilar membrane is defined as the multiplication of the equation of the velocity $v(36)$ and the equation that defines the excitation force $F$ given by

$p=\frac{F_{0}}{|Z|} \cos \left(\omega_{f} t-\Theta\right) \cdot F_{0} \cos \left(\omega_{f} t\right)$

If the equation (38) is rearranged algebraically considering trigonometric identities the following equation is obtained

$$
p=\frac{F_{0}^{2}}{|Z|}\left(\frac{1}{2} \cos \Theta+\frac{1}{2} \cos 2 \omega_{f} t \cos \Theta+\frac{1}{2} \sin 2 \omega_{f} t \sin \Theta\right)
$$

As the excitation force on the basilar membrane is a cosine function it is necessary to consider the average power $P$, which is defined as

$$
P=\frac{1}{T} \int_{t_{0}}^{t_{0}+T} p d t
$$

Substituting in this equation the expression for the power $p$ (39), the resulting integral is

$$
P=\frac{F_{0}{ }^{2}}{|Z|} \frac{1}{2} \cos \Theta+\frac{1}{T} \int_{t_{0}}^{t_{0}+T} \frac{1}{2} \cos 2 \omega_{f} t \cos \Theta d t+\frac{1}{T} \int_{t_{0}}^{t_{0}+T} \frac{1}{2} \sin 2 \omega_{f} t \sin \Theta d t
$$

The integration of the terms is zero and therefore the average power on the basilar membrane is given only by the first term.

$$
P=\frac{F_{0}{ }^{2}}{2|Z|} \cos \Theta
$$

This equation can be expressed in terms of the angular frequency $\omega=2 \pi f$ and the mechanical parameters of impedance of mass $m(x)$, damping $c(x)$, and stiffness $k(x)$ as

$$
P=\frac{F_{0}{ }^{2}}{2 \sqrt{c(x)^{2}+\left[m(x) 2 \pi f-\frac{k(x)}{2 \pi f}\right]^{2}}} \cos \Theta
$$




\section{EXPERIMENTS AND RESULTS}

The power analysis is compared with the results obtained from the finite difference method applied to the Laplace equation developed by Neely and the experimental measurements of Békesy, in all the experiments are considered the same set of frequencies described in the original papers in order to compare the results obtained with both methodologies. The first experiment is to determine the position along of the basilar membrane using the parameters of Neely where the amplitude of the equation of displacement using mechanical resonance and the amplitude of the equation of power average are maximal.
If it is considered that the magnitude of the excitation force $F_{o}$ in the stapes is normalized the equation (35) determines the frequency value of mechanical resonance where is the maximum amplitude for a specified distance of evaluation. The Figure 2 shows the results obtained for the same set of frequencies reported by Neely in his paper of $400 \mathrm{~Hz}, 570 \mathrm{~Hz}$, $800 \mathrm{~Hz}, 1130 \mathrm{~Hz}, 1600 \mathrm{~Hz}, 2260 \mathrm{~Hz}, 3200 \mathrm{~Hz}, 4520 \mathrm{~Hz}$, $6390 \mathrm{~Hz}$ and $9040 \mathrm{~Hz}$. In the axis $y$ are the values of the amplitudes $A_{x}(f, x)$ referenced to 1000nm in decibels and in axis $x$ are the values of the excitation frequencies $f$ in Hertz.

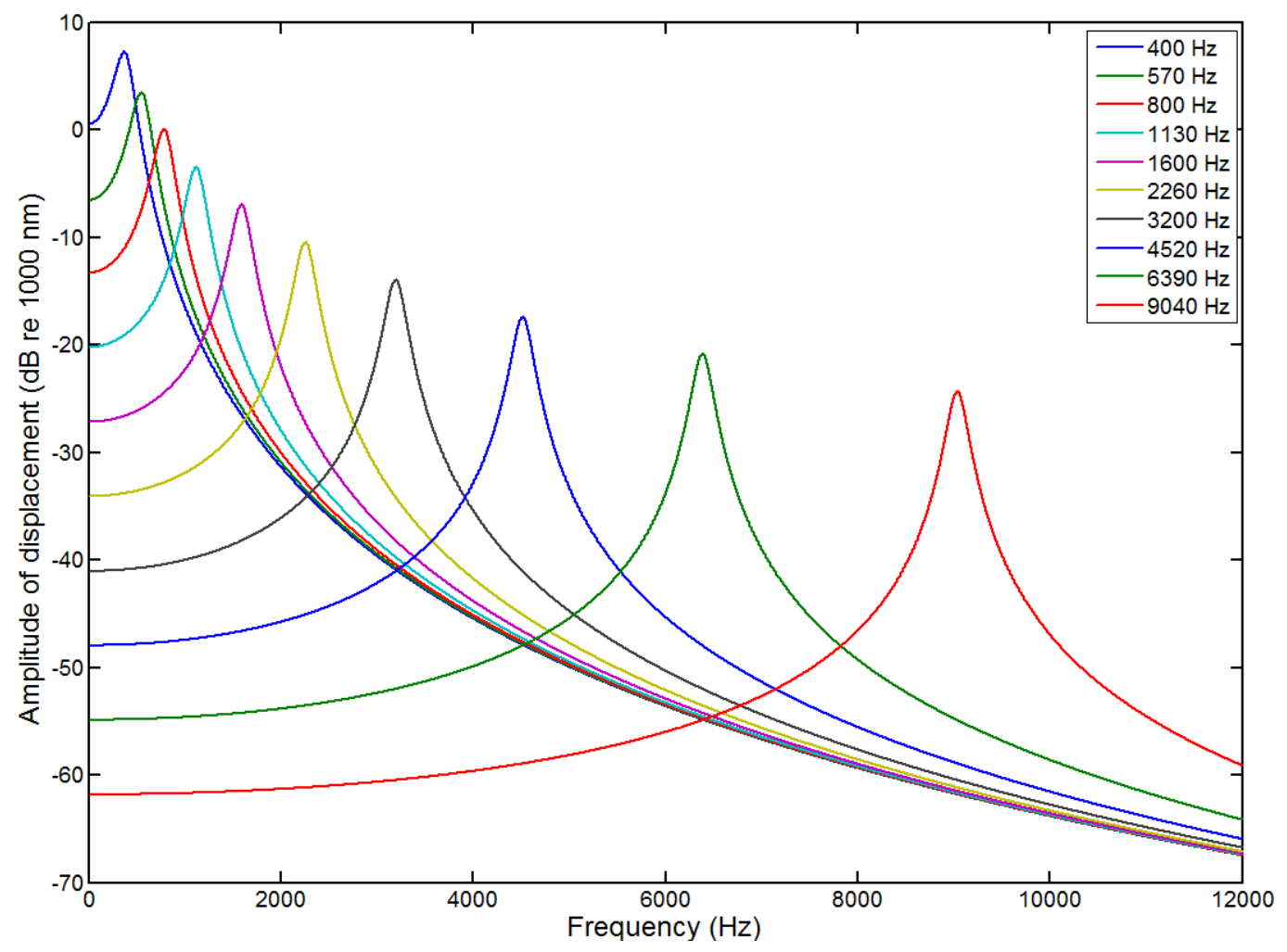

FIGURE 2. Amplitude of displacement as a function of frequency (Neely parameters). 


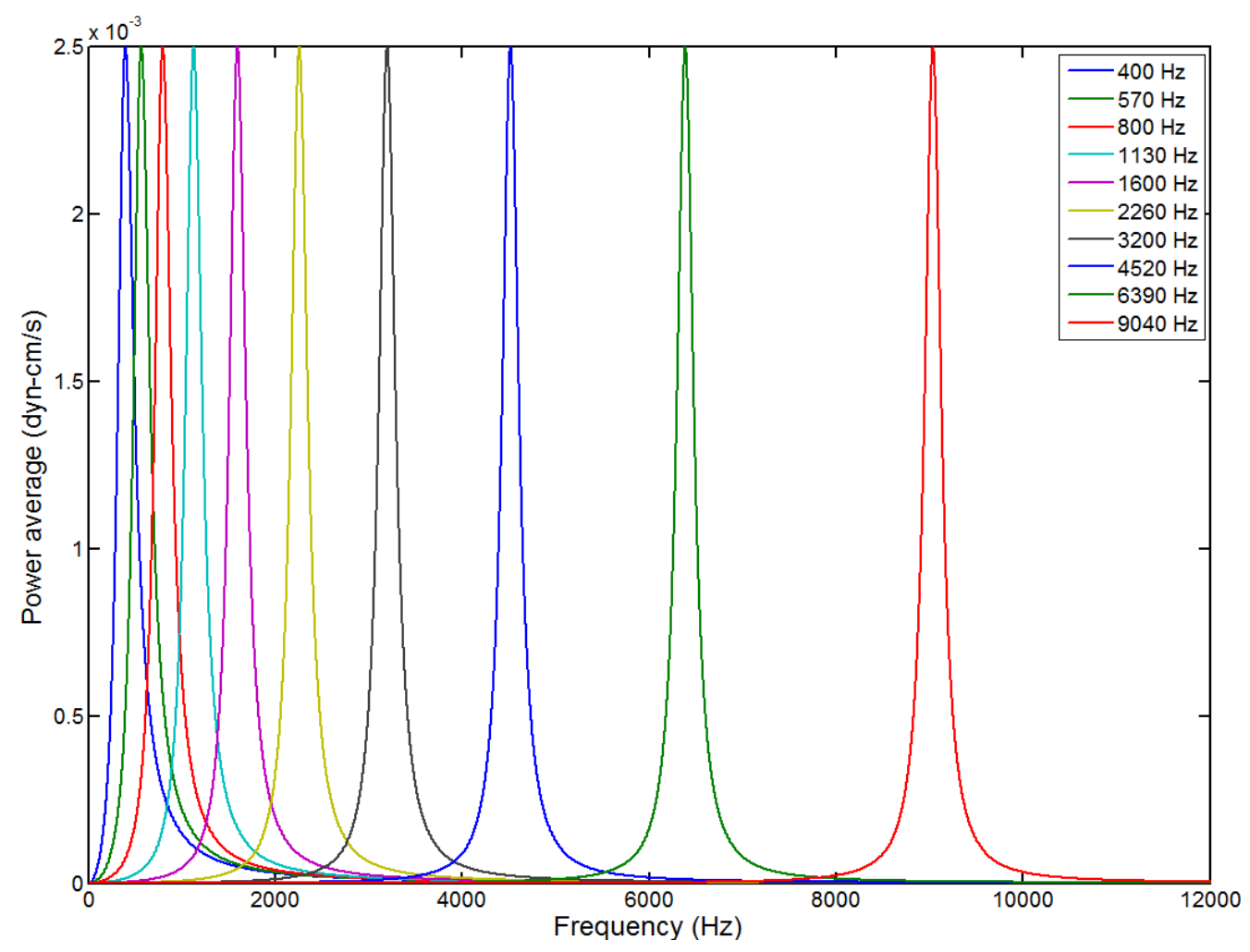

FIGURE 3. Power average as a function of frequency (Neely parameters).

The lower frequencies correspond to the position $x$ along of the basilar membrane near to the helicotrema in the cochlea and the high frequencies are in the part adjacent to the oval window which is connected to the stapes, the results of this behavior are similar to the reported by Neely. The Figure 3 shows the results obtained using the power average analysis with the equation (43) for the same set of frequencies from the previous experiment. In the axis y are the averages power $p(f, x)$ on the basilar membrane in $d y n-c m / s$ and in the axis $x$ are the values of the excitation frequencies $f$ in Hertz. As it is shown in the Figure 3 the magnitude of the power average for these specific fre- quencies has a constant value for each excitation frequency, which validates that the power exerted on each section of the basilar membrane is always the same. This condition also means that the kinetic energy is always constant, therefore this value is the energy necessary for the maximum mechanical energy transfer between the basilar membrane and the organ of Corti to activate the hair cells. The Table 3 presents the comparison between the results of the relationship frequency-distance for the function of admittance in the finite difference method developed by Neely and the methods of power analysis and mechanical resonance. 
In the results shown in the Table 3 can be seen that the distances obtained using the power analysis represent the physical behavior of the basilar membrane in the same way that the finite difference method developed by Neely, therefore the proposed methodology is validated. In a second experiment are compared the methods of average power and mechanical resonance using the mechanical parameters of Lesser and
Berkeley with the experimental results of Békésy. The Figure 4 shows the results of the mechanical resonance for the frequencies reported in the works of Békésy of $200 \mathrm{~Hz}, 400 \mathrm{~Hz}, 800 \mathrm{~Hz}, 1600 \mathrm{~Hz}$ and $2800 \mathrm{~Hz}$, again similar to the first experiment in the axis $y$ are the values of the amplitudes $A_{x}(f, x)$ referenced to $1000 \mathrm{~nm}$ in decibels and in the axis $x$ are the values of the excitation frequencies $f$ in Hertz.

TABLE 3. Power Analysis vs. Finite Difference.

\begin{tabular}{cccc}
\hline $\begin{array}{c}\text { Frequency } \\
(\mathrm{Hz})\end{array}$ & $\begin{array}{c}\text { Neely } \\
\text { Admittance } \\
\text { Distance } \\
(\mathrm{cm})\end{array}$ & $\begin{array}{c}\text { Jiménez } \\
\text { Power } \\
\text { Distance } \\
(\mathrm{cm})\end{array}$ & $\begin{array}{c}\text { Jiménez } \\
\text { Resonance } \\
\text { Distance } \\
(\mathrm{cm})\end{array}$ \\
\hline 400 & 3.5000 & 3.4800 & 3.4150 \\
570 & 3.1238 & 3.1260 & 3.0930 \\
800 & 2.8032 & 2.7880 & 2.7700 \\
1130 & 2.4424 & 2.4420 & 2.4340 \\
1600 & 2.1052 & 2.0948 & 2.0900 \\
2260 & 1.7520 & 1.7490 & 1.7470 \\
3200 & 1.4010 & 1.4013 & 1.4002 \\
4520 & 1.0500 & 1.0560 & 1.0556 \\
6390 & 0.7166 & 0.7098 & 0.7095 \\
9040 & 0.3666 & 0.3629 & 0.3628 \\
\hline
\end{tabular}

The Figure 4 shows the behavior of the function between the amplitude and frequency for the distances evaluated, this is similar to the results of the experimental measurements reported by Békésy. It is also possible to observe that the amplitude of the wave is close to helicotrema for low frequencies and is close to apex for high frequencies being this consistent with the place theory of hearing. An interesting aspect of the graphics obtained is that shows the difference of behavior between a model that uses variable damping proposed by Lesser and Berkeley respect to a model with constant damping developed by Neely. In the Figure 5 are presented the results of the power analysis for the same set of frequencies reported previously, and again similar to the graphs of the Figure 3 in the axis $y$ are the average powers $p(f, x)$ on the basilar membrane in $d y n-\mathrm{cm} / \mathrm{s}$ and in the axis $x$ are the values of the excitation frequencies $f$ in Hertz. 


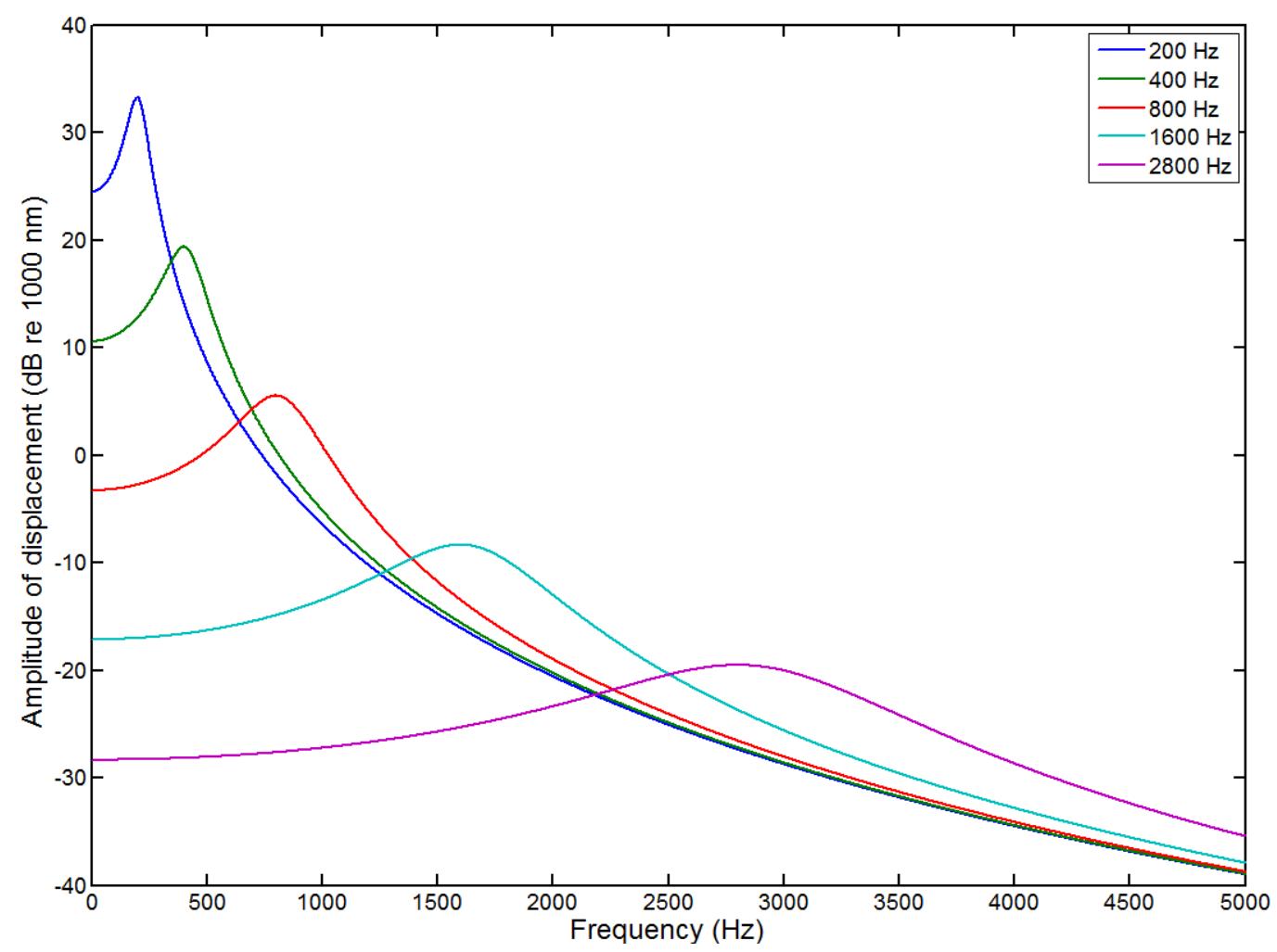

FIGURE 4. Displacement as a function of frequency (Lesser and Berkeley parameters).

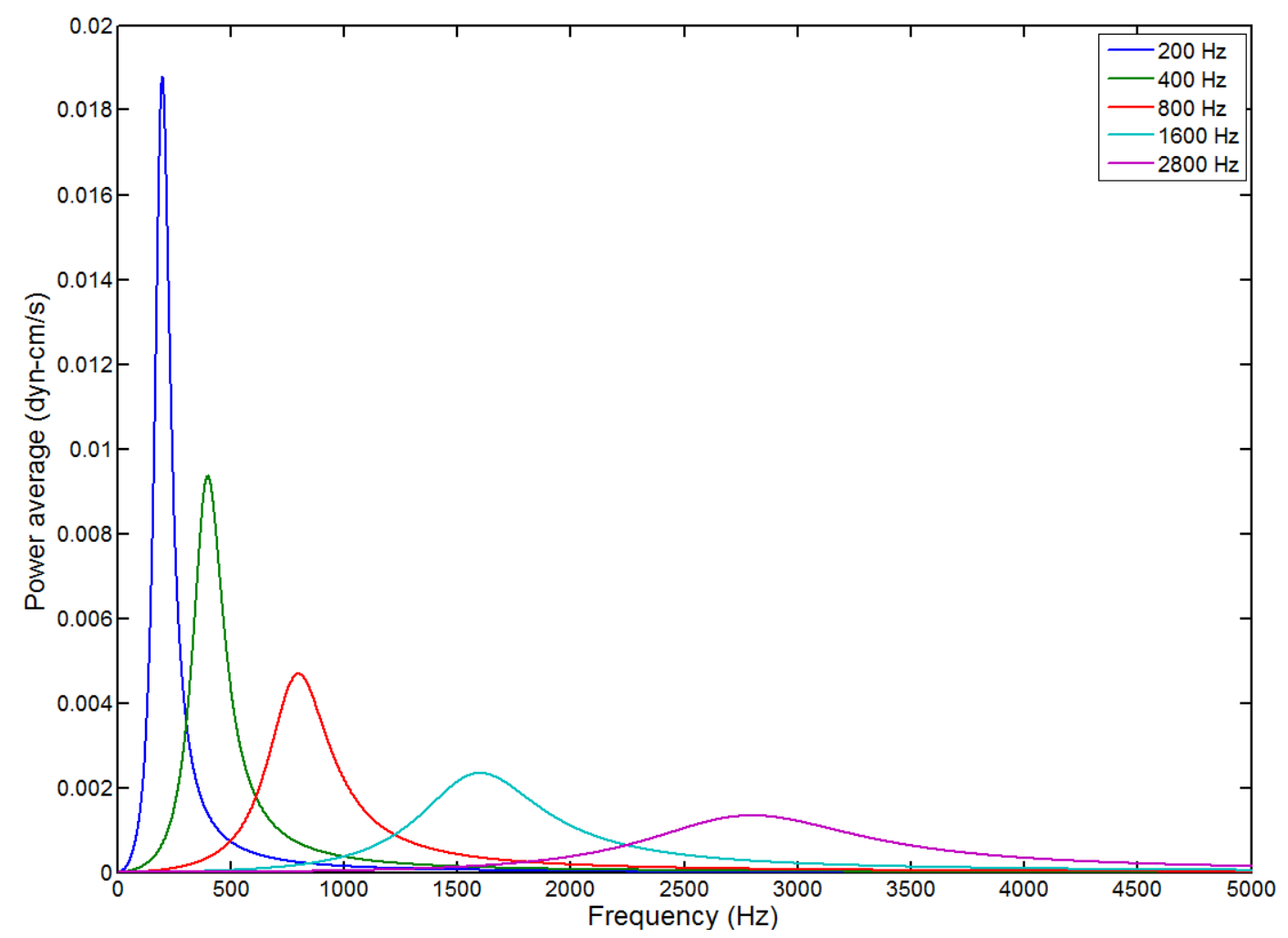

FIGURE 5. Power average as a function of frequency (Lesser and Berkeley parameters). 
The Figure 5 shows that the amplitudes of the average powers are not constant when is considering a variable damping as a function of distance. The Table 4 presents the comparison between the results obtained using the average power and the mechanical resonance using the parameters of Lesser and Berkeley with the relation frequency distance in the cochlea determined with experimental measurements by Békésy.

TABLE 4. Power Analysis vs. Experiments of Békésy.

\begin{tabular}{cccc}
\hline $\begin{array}{c}\text { Brequency } \\
(\mathrm{Hz})\end{array}$ & $\begin{array}{c}\text { Bésy } \\
\text { Distance } \\
(\mathrm{cm})\end{array}$ & $\begin{array}{c}\text { Jiménez } \\
\text { Power } \\
\text { Distance } \\
(\mathrm{cm})\end{array}$ & $\begin{array}{c}\text { Jiménez } \\
\text { Resonance } \\
\text { Distance } \\
(\mathrm{cm})\end{array}$ \\
\hline 200 & 3.1 & 3.1500 & 3.119 \\
400 & 2.4 & 2.6860 & 2.655 \\
800 & 2.0 & 2.2250 & 2.193 \\
1600 & 1.7 & 1.7624 & 1.731 \\
2800 & 1.3 & 1.3894 & 1.358 \\
\hline
\end{tabular}

\section{CONCLUSIONS}

The power analysis developed has the advantage over the previous models in two-dimensions of the cochlea of determining the relationship between the excitation frequency and the distance along of the basilar membrane where the average power is maximal. This distance represents the position where there is maximum transfer of mechanical energy between the basilar membrane and the organ of Corti necessary for the activation of the hair cells. The expression obtained for the average power depends only of the mechanical parameters of the basilar membrane of mass, damping, stiffness and the values of magnitude and frequency of the excitation force in the system.

The results in the graphics of the relationship between the amplitude of resonance and the excitation frequency (Figure 2, Figure 4) and the relationship between the average power and the excitation frequency (Figure 3, Figure 5), are fully consistent with those reported in the original works of Neely using the finite difference method (Table 3) and with the experimental measurements of Bekesy (Table 4). In both experiments the same set of frequencies of evaluation and the same mechanical parameters of the basilar membrane reported in the original papers were used in order to compare the results between the different methodologies, obtaining satisfactory results.

In the Figure 3 can be seen an interesting result of this research, this shows that the value obtained of average power for each relationship between the excitation frequency and the distance along the basilar membrane is always constant. This validates that each position along of the basilar membrane is always excited with the same kinetic energy being this value the necessary for the activation of the hair cells. In contrast the Figure 5 shows the effects of attenuation in the amplitude of the average power when the mechanical parameter of damping is variable and therefore the kinetic energy along of the basilar membrane is not constant. 


\section{REFERENCES}

1] Peterson L. C., Bogert B.P., "A Dynamical Theory of the Cochlea” J. Acoust. Soc. Amer., vol. 22, no. 3, pp. 369-381, 1950. http://dx.doi. org/10.1121/1.1906615

[2] Ranke O. F., "Theory of Operation of the Cochlea: A contribution to the Hydrodynamics of the Cochlea" J. Acoust. Soc. Amer., vol. 22, no. 6, pp. 772-777, 1950. http://dx.doi.org/10.1121/1.1906688

[3] Fletcher H., "On the Dynamics of the Cochlea" J. Acoust. Soc. Amer., vol. 23, no. 6, pp. 637-645, 1951. http://dx.doi. org/10.1121/1.1906813

[4] Zwislocki J., "Review of Recent Mathematical Theories of Cochlear Dynamics” J. Acoust. Soc. Amer., vol. 25, no. 4, pp. 743-751, 1953. http://dx.doi.org/10.1121/1.1907170

[5] Lesser M. B., Berkley D. A., "Fluid mechanics of the cochlea. Part 1” J. Fluid Mech., vol. 51, no. 3, pp. 497-512, 1972. https://doi. org/10.1017/S0022112072002320

[6] Siebert W. M., "Ranke revisited - a simple short-wave cochlear model” J. Acoust. Soc. Amer., vol. 56, no. 2, pp. 594-600, 1974. http://dx.doi.org/10.1121/1.1903296

[7] Békésy V. v., Experiments in hearing Mc Graw Hill (New York), 1960.

[8] Steele C. R., "Behavior of the basilar membrane with pure-tone excitation” J. Acoust. Soc. Amer., vol. 55, no. 1, pp. 148-162, 1974. http://dx.doi.org/10.1121/1.1928144

[9] Inselberg A., Chadwick R. S., "Mathematical model of the cochlea. I: formulation and solution" SIAM J. Appl. Math., vol. 30, no. 1, pp. 149-163, 1976. http://dx.doi.org/10.1137/0130018

[10] Chadwick R. S., Inselberg A., Johnson K., "Mathematical model of the cochlea. II: results and conclusions" SIAM J. Appl. Math., vol 30, no. 1, pp. 164-179, 1976. http://dx.doi.org/10.1137/0130019

[11] Chadwick R. S., Studies in cochlear mechanics. In: Mathematical Modeling of the Hearing Process Lecture Notes in Biomathematics, Ed: M. H. Holmes and L. A. Rubenfeld Springer-Verlag (Berlin, Heidelberg, New York), 1980.

[12] Holmes M. H., "An analysis of a low-frequency model of the cochlea” J. Acoust. Soc. Amer., vol. 68, no. 2, pp. 482-488, 1980. http://dx.doi.org/10.1121/1.384747

[13] Holmes M. H., "Low frequency asymptotics for a hydroelastic model of the cochlea" SIAM J. Appl. Math., vol. 38, no. 3, pp. 445456, 1980. http://dx.doi.org/10.1137/0138036

[14] Holmes M. H., "A mathematical model of the dynamics of the inner ear” J. Fluid Mech., vol. 116, pp. 59-75, 1982. https://doi. org/10.1017/S0022112082000366

[15] Allen J. B., "Two-dimensional cochlear fluid model: New results" J. Acoust. Soc. Amer., vol. 61, no. 1, pp. 110-119, 1977. http://dx.doi. org/10.1121/1.381272

[16] Allen J. B., Sondhi M. M., "Cochlear macromechanics: Time domain solutions” J. Acoust. Soc. Amer., vol. 66, no. 1, pp. 123-132, 1979. http://dx.doi.org/10.1121/1.383064

[17] Steele C. R., Taber L. A., "Comparison of WKV and finite difference calculations for a two-dimensional cochlear model" J. Acoust. Soc. Amer., vol. 65, no. 4, pp. 1001-1006, 1979. http://dx.doi. org/10.1121/1.382569
[18] Steele C. R., Taber L. A., "Comparison of WKV calculations and experimentals results for three-dimensional cochlear models" $J$. Acoust. Soc. Amer., vol. 65, no. 4, pp. 1007-1018, 1979. http://dx.doi. org/10.1121/1.382570

[19] Viergever M. A., Mechanics of the Inner Ear: A mathematical Approach, Delf University Press (Delf), 1980.

[20] Neely Stephen Taylor, Mathematical Models of the Mechanics of the Cochlea Engineer's Thesis, California Institute of Technology (Pasadena, California, USA ), 1978.

[21] Neely S. T., "Finite difference solution of a two-dimensional mathematical model of the cochlea" J. Acoust. Soc. Amer., vol. 69, no. 5, pp. 1386-1393, 1981. http://dx.doi.org/10.1121/1.385820

[22] Neely S. T., "Mathematical Modeling of cochlear mechanics" $J$. Acoust. Soc. Amer., vol. 78, no. 1, pp. 345-352, 1985. http://dx.doi. org/10.1121/1.392497

[23] Neely S. T., "A model of cochlear mechanics with outer hair cell motility" J. Acoust. Soc.Amer., vol. 94, no. 1, pp. 137-146, 1993. http://dx.doi.org/10.1121/1.407091

[24] Dallos P., et al. The Mechanics and Biophysics of Hearing. In: Lecture Notes in Biomathematics 87 Springer-Verlag (Berlin, Heidelberg, New York), 1990.

[25] Dallos P., Popper A. N., Fay, R. R., The Cochlea, Springer-Verlag (New York), 1996.

[26] Keener J., Sneyd J., Mathematical Physiology II: Systems Physiology Second Edition, Springer (New York), 2009.

[27] Duifhuis H., Cochlear Mechanics: Introduction to a Time Domain Analysis of the Nonlinear Cochlea, Springer (New York, Dordrecht, Heidelberg, London), 2012.

[28] Berlin C. H., Bobbin R. P., Hair Cells Micromechanics and Hearing Singular Thomson Learning (San Diego), 2001.

[29] Berlin C. H., Bobbin R. P., Hair Cells Micromechanics and Otoacustic Emission Singular Thomson Learning (San Diego), 2002.

[30] Ramamoorthy S., Deo N. V., Grosh K., "A mechano-electro-acustical model for the cochlea: Response to acoustic stimuli" J. Acoust. Soc. Amer., vol. 121, no. 5, pp. 2758-2773, 2007. http://dx.doi. org/10.1121/1.2713725

[31] Liu Y., Neely S. T., "Distortion product emissions from a cochlear model with nonlinear mechanoelectrical transduction in outer hair cells" J. Acoust. Soc. Amer., vol. 127, no. 4, pp. 2420-2432, 2010. http://dx.doi.org/10.1121/1.3337233

[32] Elliot S. J., Lineton Ben., Ni G., "Fluid coupling in a discrete model of cochlear mechanics" J. Acoust. Soc. Amer., vol. 130, no. 3, pp. 2441-2451, 2011. http://dx.doi.org/10.1121/1.3607420

[33] Guangjian Ni, Fluid Coupling and Waves in the Cochlea Doctoral Thesis, University of Southampton (Southampton, England), 2012.

[34] Jiménez H. M. et al., "Computational Model of the Cochlea using Resonace Analysis” Rev. Mex. Ing. Biomédica, vol. 33, no. 2, pp. 77-86, 2012

[35] Jiménez Hernandez Mario, Modelo mecánico acústico del oído interno en reconocimiento de voz Doctoral Thesis, Instituto Politécnico Nacional (Ciudad de México, México), 2013. 
[36] Elliot S. J., Ni G., Mace B. R., Lineton B., "A wave finite element analysis of the passive cochlea" J. Acoust. Soc. Amer., vol. 133, no. 3, pp. 1535-1545, 2013. http://dx.doi.org/10.1121/1.4790350

[37] Cormack J., Liu Y., Nam J., Gracewski S. M., "Two-compartment passive frequency domain cochlea model allowing independent fluid coupling to the tectorial and basilar membranes" J. Acoust. Soc. Amer., vol. 137, no. 3, pp. 1117-1125, 2015. http://dx.doi. org/10.1121/1.4908214

[38] Jiménez H. M., "Solution using Lagrange's Equation to the Model of Cochlear Micromechanics” Rev. Mex. Ing. Biomédica, vol. 37, no. 1, pp. 29-37, 2015. http://dx.doi.org/10.17488/RMIB.37.1.2 